\title{
Normal Response to Pregnancy in Rats Cured of Streptozotocin Diabetes by Transplantation of One Fetal Pancreas
}

\author{
J. Brown, D. Heininger, J. Kuret and Y. Mullen \\ Center for Health Sciences, UCLA School of Medicine, Los Angeles, California, USA
}

\begin{abstract}
Summary. We have investigated glucose homeostasis and insulin response to glucose in seven rats before, during and after pregnancy, who were previously successfully transplanted with a single fetal pancreas. Increased need for insulin during pregnancy provides an opportunity to test the reserve capacity of the transplanted organ. Plasma glucose in seven rats was normal before pregnancy $(7.3 \pm 0.7 \mathrm{mmol} / 1)$, during pregnancy $(6.6 \pm 1 \mathrm{mmol} / 1)$ and after parturition $(6.7$ $\pm 0.3 \mathrm{mmol} / 1)$. Fasting plasma glucose was lower after parturition $(5.1 \pm 1 \mathrm{mmol} / 1)$ than before pregnancy $(6.1 \pm 0.7 \mathrm{mmol} / \mathrm{l})$. The disappearance rate of injected glucose was the same before $(2.3 \pm 0.2 \% / \mathrm{min})$ as after pregnancy $(2.6 \pm 0.2 \% / \mathrm{min})$. Basal plasma insulin before pregnancy was elevated and there was no rise from glucose; after parturition the basal and pattern of response was normal. The total insulin content of the transplants $(859 \pm 154 \mathrm{mU}$ ) was only $21 \%$ of that of normal rats; we conclude that this provides a reserve adequate for the needs of pregnancy.
\end{abstract}

Key words: Streptozotocin induced diabetes, transplantation, fetal pancreas, pregnancy.

The altered metabolism of pregnancy results in increased insulin secretion from the pancreas. In pregnant women the basal concentration of insulin is raised and there is a progressively greater increment in plasma insulin in response to a glucose stimulus as pregnancy advances [1]. The amount of insulin required to control the blood sugar in pregnant diabetic women rises from mid-pregnancy, and often increases steadily until parturition.

Increased levels of insulin in the circulation $[2,3]$ and a two- to threefold rise in the ratio of pancreatic $B$ to A cells, have been demonstrated in pregnant rats [4, 5]. The total insulin content of the rat pancreas increases significantly up until the end of pregnancy $[2$, 3 ], and islets removed from the pancreases of preg- nant rats secrete approximately $50 \%$ more insulin in vitro than normal islets, in response to a standard glucose stimulus [6].

We have demonstrated in a rat model system [7] that one fetal pancreas transplanted into a diabetic animal is capable of completely reversing the diabetic state $[8,9]$. The insulin content of fetal pancreatic transplants removed from recipient rats after 2.5 to 9 months is approximately $22 \%$ of that of a normal adult pancreas. The increased need for insulin during pregnancy thus provides an opportunity to test the reserve capacity of the transplanted pancreas. This was undertaken by mating female rats after successful transplantation and observing the effects of pregnancy on the metabolic state.

\section{Materials and Methods}

\section{Animals}

Severe diabetes was induced in adult female Lewis rats by an IV injection of streptozotocin $(90 \mathrm{mg} / \mathrm{kg})$. The animals were weighed every 5-10 days and kept in metabolic cages. Random plasma glucose levels of tail vein blood were measured weekly on a Beckman glucose analyzer, and urine was collected daily to measure volume and glucose excretion.

After 2 weeks of observations to establish the severity of diabetes, the animals were started on daily injections of 3 units of protamine zinc insulin. Then, 14 days later, a syngeneic fetal pancreas of 17-171/2 days' gestation was transplanted beneath the kidney capsule. Insulin injections were administered in decreasing doses as the severity of diabetes lessened, and discontinued when the plasma glucose was under $14 \mathrm{mmol} / 1$.

After complete return of blood and urine glucose to normal (53 \pm 10 days, mean \pm SD) seven female rats were mated with fertile male Lewis rats; pregnancy occurred $40 \pm 13$ days after the last injection of insulin (range 27-62 days). Following spontaneous delivery, the rats were observed for an additional period of $48 \pm 32$ days (range 12-75 days) after which the grafts were removed from under the kidney capsule, immediately frozen on dry ice, and stored at $-70^{\circ} \mathrm{C}$. Following removal of the transplanted pancreas, ketones were estimated daily in the blood and urine using acetest tablets (Ames, Elkhart, Indiana, USA). In addition, plasma glucose and urine volume and glucose were measured. 


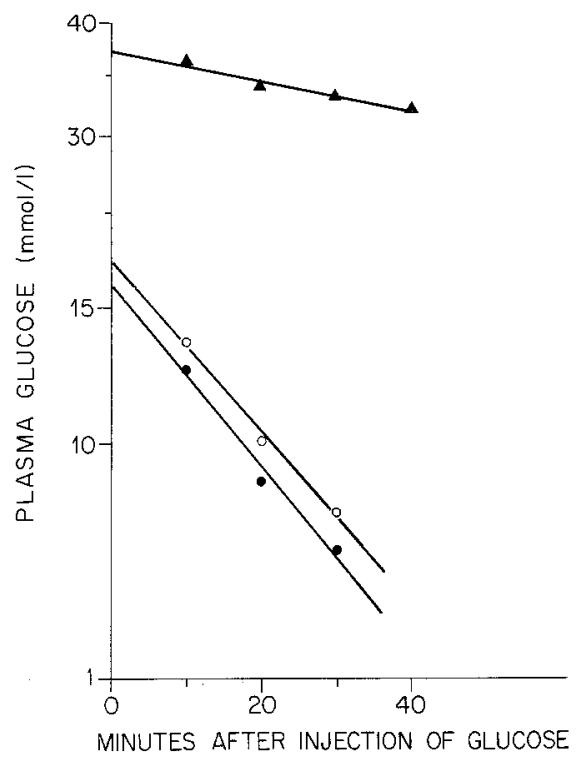

Fig. 1. Glucose disappearance rate (IV glucose tolerance test) after reversal of diabetes following transplantation of a fetal pancreas (O--O, pre-pregnancy) compared with the rate following parturition (-- post-pregnancy). Comparison is made with untreated diabetic rats one month after streptozotocin $(\mathbf{\Lambda}-\mathbf{\Lambda})$. The $\mathrm{k}$ value pre-pregnancy $(2.3 \pm 0.2 \% / \mathrm{min})$ was the same as post-pregnancy $(2.6 \pm 0.2 \% / \mathrm{min})$ compared with the rate for diabetic controls $(0.5 \% / \mathrm{min})$

Table 1. Plasma insulin response to glucose injection in transplanted diabetic rats before and after pregnancy compared with normal control rats

\begin{tabular}{|c|c|c|c|}
\hline \multirow{2}{*}{$\begin{array}{l}\text { Minutes after } \\
\text { glucose } \\
\text { injection }\end{array}$} & \multicolumn{2}{|c|}{ Transplanted diabetic rats } & \multirow{2}{*}{$\begin{array}{l}\text { Normal } \\
\text { control rats } \\
(n=6) \\
(\mathrm{mU} / 1)\end{array}$} \\
\hline & $\begin{array}{l}\text { Pre-pregnancy } \\
(n=3) \\
(\mathrm{mU} / \mathrm{l})\end{array}$ & $\begin{array}{l}\text { Post-pregnancy } \\
(n=5) \\
(\mathrm{mU} / 1)\end{array}$ & \\
\hline 0 & $80 \pm 16$ & $64 \pm 13$ & $44 \pm 4$ \\
\hline 10 & $76 \pm 8$ & $97 \pm 18$ & $62 \pm 6$ \\
\hline 20 & $75 \pm 5$ & $65 \pm 12$ & $59 \pm 9$ \\
\hline 30 & $66 \pm 4$ & $59 \pm 15$ & $48 \pm 6$ \\
\hline 40 & $78 \pm 12$ & $52 \pm 10$ & $39 \pm 6$ \\
\hline
\end{tabular}

Results expressed as mean \pm SEM

\section{Assay Procedure}

The frozen pancreases were homogenized in cold acid-alcohol and extracted overnight at $4{ }^{\circ} \mathrm{C}$ for insulin assay. The insulin content was measured by radioimmunoassay against a rat insulin standard (Novo Industri, Copenhagen). The extracts were assayed in duplicate at three or more dilutions.

\section{Glucose Tolerance Tests}

Glucose tolerance tests were performed 15-25 days before pregnancy and 8-48 days after parturition; none of the mothers were nursing. Rats were fasted overnight, weighed and, while restrained in a towel wrap, given D-glucose in a dose of $0.5 \mathrm{~g} / \mathrm{kg}$ body weight by a rapid injection into the tail vein. Without restraining the animals, blood samples ( $250 \mu$ into heparinized tubes) were collected from the tail vein before glucose injection and at 10,20,30 and $40 \mathrm{~min}$ after injection. After separation of plasma, glucose content was determined (Beckman glucose analyzer) and the remaining plasma was frozen for radioimmunoassay of insulin content as above. The $k$ value for the rate of glucose disappearance was determined using the 10,20 and 30 min values. This method for measurement of glucose disappearance without anaesthesia or restraint does not affect the $k$ value for glucose disappearance, but it reduces the peak insulin concentration modestly compared with values using chronic indwelling catheters [10]. Normal control rats of the same age and sex were subjected to the glucose tolerance study, and untreated, control diabetic rats were studied one month after streptozotocin injection.

\section{Results}

\section{Plasma and Urine Studies}

Plasma glucose (random) levels in the untreated diabetic rats of $29.4 \pm 5.6 \mathrm{mmol} / 1$ fell to normal $(7.3 \pm$ $0.7 \mathrm{mmol} / 1)$ at $53 \pm 10$ days following transplantation (pre-pregnancy) and remained the same during pregnancy $(6.6 \pm 1 \mathrm{mmol} / \mathrm{l})$. The plasma glucose did not change following parturition $(6.7 \pm 0.3 \mathrm{mmol} / \mathrm{l})$, but after removal of the transplants it returned almost to the pre-transplant concentration $(24.6 \pm 0.3 \mathrm{mmol} /$ 1). Fasting blood glucose before pregnancy was $6.1 \pm$ $0.7 \mathrm{mmol} / 1$ and tended to be lower following parturition $(5.1 \pm 1 \mathrm{mmol} / \mathrm{l})$. Urine volume was $99 \pm 16 \mathrm{ml} /$ day before transplantation and fell to normal (12 \pm $3 \mathrm{ml} /$ day) afterwards. Following removal of the transplants, the volume of urine increased rapidly to $102 \pm$ $29 \mathrm{ml} /$ day, the same as that measured before transplantation. Glucose excretion in the urine, which was $8.6 \pm 1 \mathrm{~g} /$ day before transplantation, was absent af ter transplantation but returned to pretransplant levels $(8.0 \pm 1.6 \mathrm{~g} /$ day $)$ after removal of the transplant. Plasma and urine were tested for ketones in six rats after transplant removal. Ketones were positive in both plasma and urine in four rats, but in the other two they were positive in either the urine or the serum.

\section{Glucose Tolerance Tests}

The rate of glucose disappearance from the blood $(k$ value) after its injection, was $2.3 \pm 0.2 \% / \mathrm{min}$ in the transplanted rats before pregnancy (Fig. 1). This is not different from the rate in normal control rats of the same strain, age and sex $(2.5 \pm 0.1 \% / \mathrm{min})$ [11]. Following parturition and after weaning, the mean rate of glucose disappearance was unchanged ( $2.6 \pm$ $0.2 \% / \mathrm{min}$ ). The rates of glucose disappearance before and after pregnancy for each individual rat were compared using the paired Student's t test and revealed no significant difference; but in all cases the disappearance rate was faster following pregnancy.

Plasma insulin concentration before pregnancy revealed a mild elevation of basal insulin with no rise following glucose injection (Table 1). Following pregnancy the basal level was lower and there was a normal rise following glucose injection. The insulin levels tended to be higher than in normal control rats $(p=$ NS). 
We weighed the rats frequently before, during and after pregnancy as an index of the normality of adjustment to pregnancy. The mean weight gain of the seven rats at the end of pregnancy was $37 \pm 13 \mathrm{~g}$, which is close to the normal range of 25-30 g [12]. Following parturition there was a weight loss of $19 \pm 16 \mathrm{~g}$ and the weight curve of all rats was level thereafter until removal of the graft.

Total insulin content in the transplants removed from this group of rats $130 \pm 42$ days after grafting was $859 \pm 154 \mathrm{mU}$. This is $21 \%$ of the insulin content of the pancreases removed from normal female rats of the same age and strain [9].

\section{Discussion}

Severe diabetes was produced in rats by injecting a large dose of streptozotocin, which depleted the pancreas of approximately $95 \%-98 \%$ of its insulin content [13]. The severity of the diabetes was confirmed following removal of the transplants, at which time blood glucose, urine volume, and glucose excretion returned to pre-transplant levels. Also, in six of the seven rats tested, ketones were present in blood or urine.

The findings of the present study indicate that the metabolic adjustment to pregnancy of our diabetictransplanted rats was normal. Plasma glucose measured in the fed state was the same before, during and after pregnancy. The gain in body weight during pregnancy was also normal. Pregnancy did not result in any deterioration of metabolic function, and there were some suggestions that the function of the transplanted pancreas was improved following parturition.

Evidence for this comes from the trend of mean fasting blood glucose for the group and $k$ values when compared in individual animals. Although the differences are not statistically different the values are all lower after pregnancy. Somewhat stronger evidence is the change in basal and glucose stimulated insulin levels. Prior to pregnancy the basal insulin is elevated and there is no rise in response to glucose. This is the pattern observed in an earlier study in which blood glucose levels were not completely controlled and suggested chronic overstimulation of insulin secretion and lack of pancreatic insulin reserve [10]. Following pregnancy, basal insulin levels were lower but a clear response to glucose was seen. The pattern of response to glucose injection was similar to that of normal animals except that all insulin levels tended to be higher than normal. The reason for this elevation is very likely to be due to the route of insulin drainage from the transplants into the renal vein, bypassing the liver [14].
Since the insulin content of the transplants was $21 \%$ of the insulin content of pancreases removed from rats of the same age, sex and strain, we conclude that this amount of functioning pancreatic tissue is adequate to maintain normal glucose homeostasis during pregnancy.

Acknowledgements. The authors wish to thank Linda Olt for editorial assistance and Charlotte Limberg and Pam Meyers for secretarial services. The work was supported by grants AM 17980 and AM 20827 from the National Institutes of Health.

\section{References}

1. Pederson J (1977) The pregnant diabetic and her newborn. Williams and Wilkins, Baltimore, $\mathrm{p} 30$

2. Malaisse WJ, Malaisse-Lagae F, Picard C, Flament-Durant J (1969) Effect of pregnancy and chorionic growth hormone upon insulin secretion. Endocrinology 84: 41-44

3. Green IC, Taylor KW (1972) Effects of pregnancy in the rat on the size and insulin secretory response of the islets of Langerhans. J Endocrinol 54:317-325

4. Hellman B (1960) The islets of Langerhans in the rat during pregnancy and lactation with special reference to the B/A cell ratio. Acta Obstet Gynecol Scand 29:331-342

5. Aerts L, Van Assche FA (1975) Ultrastructural changes of the endocrine pancreas in pregnant rats. Diabetologia 11:285-289

6. Kalkhoff RK, Kim HJ (1979) The influence of hormonal changes of pregnancy on maternal metabolism. Ciba Found Symp 63: 29-56

7. Brown J, Molnar IG, Clark W, Mullen Y (1974) Control of experimental diabetes mellitus in rats by transplantation of fetal pancreases. Science 184: 1377-1379

8. Mullen YS, Clark WR, Molnar IG, Brown J (1977) Complete reversal of experimental diabetes mellitus in rats by a single fetal pancreas. Science 195: 68-70

9. Brown J, Heininger D, Kuret J, Mullen Y (1981) Islet cells grow after transplantation of fetal pancreas and control diabetes. Diabetes 30:9-13

10. Brown J, Mullen Y, Clark WR, Molnar IG, Heininger D (1979) Importance of hepatic portal circulation for insulin action in streptozotocin-diabetic rats transplanted with fetal pancreases. J Clin Invest 64: 1688-1694

11. Brown J, Clark WR, Molnar IG, Mullen YS (1976) Fetal pancreas transplantation for reversal of streptozotocin-induced diabetes in rats. Diabetes 25:56-64

12. Farris EJ (1967) Breeding of the rat. In: Farris EJ, Griffith JQ Jr (eds) The rat in laboratory investigation. Hofner, New York, pp 1-18

13. Junod A, Lambert AE, Stauffacher W, Renold AE (1969) Diabetogenic action of streptozotocin: relationship of dose to metabolic response. J Clin Invest 48:2129-2139

14. Field JB (1972) Insulin extraction by the liver. In: Handbook of physiology 1, Section 7. Waverly Press, Baltimore, pp 505-514

Received: 27 November 1980

and in revised form: 20 July 1981

Josiah Brown, M.D.

Department of Medicine

University of California at Los Angeles

School of Medicine

Los Angeles, California 90024, USA 